\title{
Business in the Hands of Consumers: A Scale for Measuring Online Resale Motivations
}

\author{
Myriam ERTZ ${ }^{*}$, Fabien DURIF ${ }^{2}$ and Manon ARCAND ${ }^{2}$ \\ ${ }^{1}$ University of Quebec in Chicoutimi, Canada \\ ${ }^{2}$ University of Quebec in Montreal, Canada
}

\begin{abstract}
The web channel is increasingly a central aspect of the second-hand economy and, as such, favours also more sustainable post-consumption processes. This is why the field of online reselling appears increasingly important. Besides, the ever broadening scope of online reselling is key to the success of new online intermediaries that position themselves in the broader movement of collaborative consumption. While, consumers' attachment for second-hand exchanges is not new, they have largely embraced its online declination. In response to these evolutions in the online retail environment, traditional retail companies have therefore started to create online consumer marketplaces in which consumers exchange goods by themselves. In order to best adapt such online marketplaces to consumers, it is therefore critically important to gain a better understanding of the driving forces behind online reselling. At present, knowledge about what motivates consumers to resell products online is limited. This article outlines the development and validation process of an online resale motivation (ORM) scale via three studies involving 1,119 respondents. Study 1 presents the ORM scale development process and resulting multi-dimensional construct, including protester, economic, generative, recreational, practical and social facets. Study 2 replicates the scale and investigates its predictive capabilities. More specifically, the ORM scale predicts successfully online resale frequency. Consumers who are more highly motivated to resell online, will indeed resell more often online. Study 3 examines the mediating role of ORM on the relationship between planned resale intentions (PRI) and online resale behaviour. The fact that consumers plan to resell a product prior to its purchase, will not directly lead them to increase the frequency at which they resell online. Rather, it is because they perceive positive economic, practical and recreational outcomes associated with online reselling that they resell more frequently online the goods which they intended to resell prior to their purchase.
\end{abstract}

Keywords: online resale, online reselling motivations, measurement scale, planned resale intentions, online resale frequency

JEL Classification: M31

\footnotetext{
${ }^{*}$ Corresponding Author:

Myriam Ertz, Department of Economics and Administrative Sciences, University of Quebec in Chicoutimi, 555 Boulevard de l'Université, Chicoutimi, QC, G7H 2B1, Canada 


\section{Introduction}

The literature has emphasized the growth of the broad web-fueled movement of collaborative consumption which on the one hand increases consumers' capability to access or share resources instead of merely possessing them (McArthur, 2015; Matzler, Veider and Kathan, 2015; Ozanne and Ballantine, 2015; Watkins, Denegri-Knott and Molesworth, 2016) and, on the other, democratizes the ownership of any type of good through alternative consumption marketplaces such as secondhand ones (Botsman and Rogers, 2010; Belk, 2014). Within that bigger technology-enabled consumption phenomenon, there appears therefore to be a growing popularity of online reselling (e.g. online auctions) (Korgaonkar et al., 2014; Kijiji, 2015, 2016). According to the American National Retail Federation, for example, a website such as Amazon, which allows resales, had a $22.6 \%$ sales growth from 2013 to 2014, which surpasses by far flourishing retailers such as Kroger (10.1\%), Costco (6.6\%), The Home Depot (3.6\%), Apple Store/iTunes (6.5\%) and less successful ones such as Sears $(-11.8 \%)$ or Safeway $(-2.1 \%)$ (Top 100 Retailers chart, 2015). Besides, some companies have already engaged efforts to incorporate this new form of marketing system, driven by consumers and nurtured by online platforms, into their business models. Patagonia, for example, has created a customer marketplace by partnering with eBay to encourage consumers to buy and sell their pre-owned goods (Vision Critical and Crowd Companies, 2014, p.10).

However, while much is presently known about second-hand purchases, little work has been undertaken in order to understand reselling. Online resale is even less covered in the literature. This contrasts sharply with the thorough coverage of conventional online retail in the literature that has been taking place for the last 15 years (Insley and Nunan, 2014; Nicholson, Clarke and Blackmore, 2002; Cases, 2002). Given that the web channel is now a central aspect of the second-hand economy, the field of online reselling is of increasing important. This ever broadening scope of online reselling is key to the success of new online intermediaries that position themselves as facilitators instead of retailers. Traditional retailing companies view therefore the second-hand market as a threat to their business given its potential to curtail the sale of new goods. Thus, it is critically important to gain a better understanding of the driving forces behind online reselling.

The coverage of online resale motivations is however barely emerging in the literature. First, much of the emerging research in $\mathrm{C} 2 \mathrm{C}$ marketing systems examines their structures and consumer profiles (Zhang, 2015; Azad, Islam and Hoque, 2014). Yet, the evolution of markets, including C2C markets, requires not only buyers but also sellers (Agarwal and Gort, 1996). It is therefore equally important to clarify the complex motives that explain why people might resell online in addition to purchasing online. Second, the study on online reselling remains confined to the Asian context (e.g. Azad, Islam and Hoque, 2014; Zhang, 2015; Chu and Liao, 2007). Third, studies devoted to identify the antecedents to online study focus on utilitarian aspects such as pricing and value recovering considerations (Chu and Liao, 2010; Chu, 2013; Liao and Chu, 2013; Murphy and Liao, 2013), although recent works pinpointed hedonic and even ideological aspects related to such a practice (Zhang, 2015).

In an attempt to reconcile these various gaps in the literature, our findings expand exploratory conclusions about offline resale motivations, in an online context. It appears that in addition to the protester, economic, generative and recreational factors identified as motivations for offline reselling (e.g. Gregson et al., 2007; Hanson, 1980; Lemaitre and de Barnier, 2015), online reselling is also prompted by practical and social motivations. Third, although having been related to mental accounting theory (Chu and Liao, 2010; Liao and Chu, 2013), no research has investigated the extent to which planned resale intentions modulate the relationship between online resale motivations and online resale intensity. By investigating the role of online resale motivations, we help clarify the conditions under which the links between planned resale intentions and online resale frequency might be enhanced.

\section{Conceptual Background}

\subsection{Online Resale}

Originally, online reselling was examined through the lenses of auctions studies (e.g. eBay) (Korgaonkar et al., 2014). Online reselling is however increasingly popular on C2C classified ads websites (e.g. Kijiji, Craigslist, Amazon). What was once a marginal form of disposition, comprising flea markets (Sherry, 1990), garage sales (Soiffer and Herrmann, 1987), car boot sales (Stone et al., 1996) or swap meets (Belk et al., 1988), has become, in both Europe, and North America, a booming trend thanks to the rise of Web 2.0 and social media (Lemaitre and de Barnier, 2015; Belk, 2014). Online reselling is the transposition of previously marginal markets on the world wide web. It is also relevant to retail, in general, and online retail, 
in particular, since it is web-mediated - a technological dimension -, enables other consumers not buying new, but used or pre-owned products - a product dimension -, and represents a channels with distinctive characteristics - a sales dimension.

Therefore, we define Online Resale (OR) as a disposal option which enables consumers to dispose of an item permanently by using the Internet to resell it directly to other consumers. We do not consider both online and offline channels interchangeably, rather we investigate the specificities of online resale.

\subsection{Online Resale Motivations}

According to expectancy theory, people are driven by expectations - positive incentives - as opposed to being merely pushed from within (Porter and Lawler, 1968; Vroom, 1964). Also, the effects of outcome expectancies are partly governed by self-beliefs of efficacy (i.e. agency) (Bandura, 1977, 1989). Porter and Lawler (1968), refined that theory by stating that the expenditure of an individual's effort will be determined by expectations of desirable outcomes for that individual. Hence, the motivation of the behaviour choice is determined by the desirability of the outcome (Porter and Lawler, 1968). It then follows that resellers choose (i.e. have the desire to expend energy and effort) in online resale given that they expect that choice to result in a more positive outcome for them. Such prospects raise consumers' propensity to favour online reselling. It then appears of interest to uncover the dimensionality of those positive outcomes that are sought by consumers through online reselling since they condition the process of energy and effort being mobilized.

For the purpose of this research, we define Online Resale Motivations (ORM) as the positive outcomes that lead a consumer to mobilize efforts to move from a state of product ownership to a state of product 'disownership' through the online resale of that product. We attempt to develop and validate a measurement scale of the motivations for online resale. This scale comprises dimensions of positive outcomes that consumers may perceive to be related to OR and which lead them to expend energy and effort to engage in OR, in order to get rid of their unwanted or unneeded products.

\section{Study 1: Scale Development}

Study 1 entailed the development of an online resale motivation scale based on the procedure recommended by Churchill (1979) as well as Gerbing and Anderson (1988).

\subsection{Methodology}

Construct domain and item generation. A two-stage qualitative study of a focus group and 15 in-depth interviews were conducted among Canadian online resellers. The interviews were recorded and transcribed. This procedure respects the information saturation principle (Glaser and Strauss, 1967). That is, the interviews did not yield additional or new information or insight to enrich previous findings. Sequential coding was then performed to organize raw qualitative data into conceptual categories also called codes (Miles and Huberman, 1994), which brought out certain themes. Those themes guided our choice of subsequent respondents in the following interviews (Strauss and Corbin, 1990). A convenience sampling procedure was conducted to recruit online resellers.

The exploratory process resulted in the identification of six main motivation areas: (1) economic: the collection of money in exchange of the product; (2) protester: enabling others to circumvent conventional marketing systems and to avoid new purchases; (3) generative: extending the lifecycle of the product by making it available for others; (4) recreational: the inherent pleasure of engaging in an informal commercial exchange; (5) practical: getting rid easily of unwanted products; and (6) social: the prospect of interacting with others. Those six motivation areas resulted in the generation of 30 items.

Content-validity judging. Five consumer behaviour faculty members (full professors), specialized in marketing, evaluated the items for content and face validity. They were given the conceptual definitions of the motivations, along with illustrative quotes from the qualitative data, and were instructed to rate items as "not at all representative" "rather representative" or "very representative". This process resulted in the deletion of seven ambiguous or irrelevant items.

Substantive validity. A group of three other marketing academics were provided with the refined 23item scale and asked to assign each item to the construct that they thought, the item best reflected. The proportion of substantive agreement which refers to the ratio of the number of participants assigning an item to its intended construct on the total number of participants (Anderson and Gerbing, 1991), averaged .61, which is nearer to 1 than to 0 , providing preliminary evidence of substantive validity. Secondly, the substantivevalidity coefficient, which refers to the extent to which participants are more likely to assign an item to its intended construct rather than to any other construct (Anderson and Gerbing, 1991), averaged .57, which is above the recommended threshold value of 0.5 . Thus, both indices provide evidence for substantive validity. 
Data collection. Exploratory data was gathered to test the initial proposed structure. Members ( $\mathrm{n}=$ 1,100) of a Canadian online consumer panel were contacted and 477 answered the survey ( $43 \%$ response rate). Only respondents who indicated that they had sold second-hand items online in the past twelve months were eligible. We investigated online reselling behaviour for the period of twelve months prior to the conduct of the survey. According to the 'recency principle' (d'Astous et al., 2010, p. 78), twelve months is deemed a reasonable timeframe for consumers to recall the specifics of resale transactions. The same sampling approach was used in studies 2 and 3. The description of the sample is as follow: $49 \%$ male, 4\% were 15-24 years old, $39 \%$ were $25-44,41 \%$ were $45-64$, and $16 \%$ were 65 and over; $58 \%$ had at least a college or university degree. We measured the 23 items of the online resale motivation scale on a ten-point scale ( 1 = 'Totally disagree' and $10=$ 'Totally agree'). The same measure was used in studies 2 and 3.

\subsection{Analysis and Results}

Exploratory factor analysis. An exploratory factor analysis (EFA) (SPSS 23.0) confirmed the sixfactor model for ORM. About $81 \%$ of total variance was explained and no item cross-loaded on several factors. The appropriateness of a six-factor structure is ensured since all factors have Eigenvalues above 1.0, and the Cattell test, which indicates graphically the appropriate number of factors before the curve marks an elbow (Hair et al., 2006), started at seven, which indicates that the six-factor solution is the most adequate. Further criteria for scale development were met since all items exhibited item-to-total-correlations and communalities higher than .5, and the Cronbach's alpha for the 23-item scale was .946 (Nunnally and Bernstein, 1994).

Confirmatory factor analysis. A confirmatory factor analysis (CFA) (LISREL 8.8) was used to refine the scale and assess dimensionality (Gerbing and Anderson, 1988). Items were eliminated if their standardized factor loadings were lower than 0.70 (Shimp and Sharma, 1987), which resulted in the removal of three items. In the final 20-item model, each factor includes 3 or 4 items which ensures that the model is specified (Bollen, 1989). The proposed scale (see Table 1, column 2) explains $86 \%$ of the variance with excellent fit to the data $\left(\chi^{2}(155)=294.16, \mathrm{p}<.001, \mathrm{NFI}=.98, \mathrm{NNFI}=.99, \mathrm{CFI}=.99 ; \mathrm{IFI}=.99 ; \mathrm{RFI}=.98 ; \mathrm{GFI}=.94 ; \mathrm{AGFI}=.92\right)$. Residuals are low, with an RMSEA of .044, below the .5 threshold indicating "excellent" fit (Browne and Cudek, 1992) and an SRMR of .042, well below the cut-off level of .10 (Hong and Thong, 2013).

Table 1. Model item loadings of ORM and alpha coefficients for the three studies

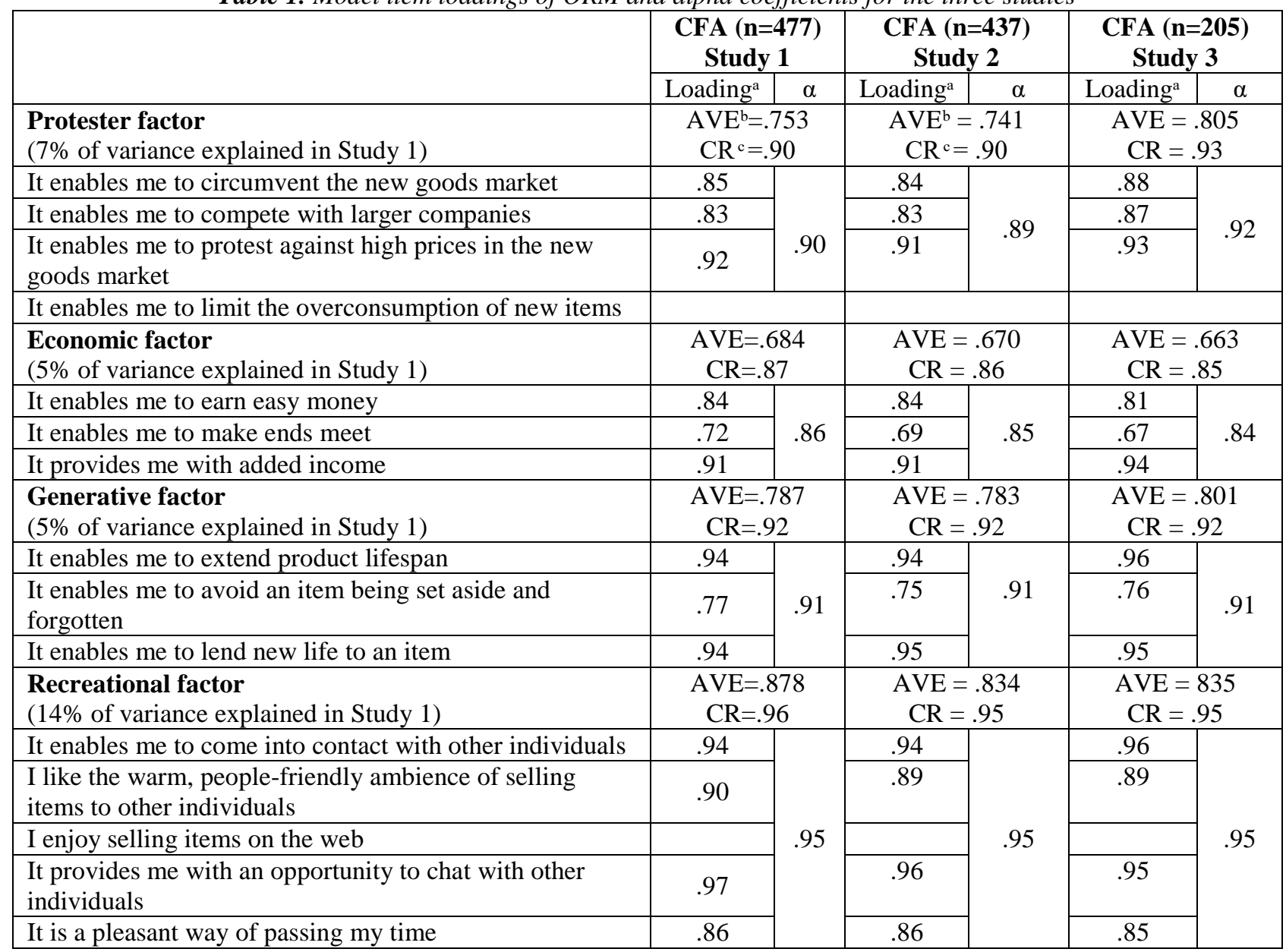




\begin{tabular}{|c|c|c|c|c|c|c|}
\hline $\begin{array}{l}\text { Practical factor } \\
(9 \% \text { of variance explained in Study } 1)\end{array}$ & \multicolumn{2}{|c|}{$\begin{aligned} \mathrm{AVE} & =.847 \\
\mathrm{CR} & =94\end{aligned}$} & \multicolumn{2}{|c|}{$\begin{aligned} \mathrm{AVE} & =.835 \\
\mathrm{CR} & =.94\end{aligned}$} & \multicolumn{2}{|c|}{$\begin{aligned} \mathrm{AVE} & =.853 \\
\mathrm{CR} & =.95\end{aligned}$} \\
\hline Helps me keep things tidy at home & .95 & \multirow{3}{*}{.94} & .94 & \multirow{3}{*}{.94} & .94 & \multirow{3}{*}{.95} \\
\hline Helps me declutter & .90 & & .90 & & .93 & \\
\hline Helps me sort things out on the home front & .91 & & .90 & & .90 & \\
\hline \multicolumn{7}{|l|}{ Helps me effect change } \\
\hline $\begin{array}{l}\text { Social factor } \\
(46 \% \text { of variance explained in Study } 1)\end{array}$ & \multicolumn{2}{|c|}{$\begin{aligned} \mathrm{AVE} & =.838 \\
\mathrm{CR} & =.95\end{aligned}$} & \multicolumn{2}{|c|}{$\begin{aligned} \mathrm{AVE} & =.834 \\
\mathrm{CR} & =.95\end{aligned}$} & \multicolumn{2}{|c|}{$\begin{aligned} \mathrm{AVE} & =.798 \\
\mathrm{CR} & =.94\end{aligned}$} \\
\hline $\begin{array}{l}\text { It enables me to help out individuals less fortunate than } \\
\text { myself }\end{array}$ & .87 & \multirow{4}{*}{.96} & .86 & \multirow{4}{*}{.95} & .85 & \multirow{4}{*}{.94} \\
\hline It gives me the impression of helping my fellow citizens & .92 & & .92 & & .87 & \\
\hline $\begin{array}{l}\text { It gives me the impression of doing something good for } \\
\text { society }\end{array}$ & .94 & & .94 & & .92 & \\
\hline $\begin{array}{l}\text { It gives me the impression of doing something good for } \\
\text { the community }\end{array}$ & .93 & & .93 & & .93 & \\
\hline
\end{tabular}

Note : ${ }^{a}$ All factor loadings are significant at $\mathrm{p}<.001$ (p-values are higher than 2.58 in absolute value); ${ }^{b}$ AVE : Average Variance Extracted (Rho vc); ${ }^{\mathrm{c}} \mathrm{CR}$ : Composite Reliability (Joreskog rho).

Reliability and validity. The final scale of 6 dimensions and 20 items displayed satisfactory reliability scores, above 0.70, and each item having an item-to-total correlation above .5, indicating high internal consistency (Nunnally and Bernstein, 1994). The three conditions for convergent validity were all fulfilled, since each item lambda coefficient was above 0.7, significant at the .001 level, and was greater than twice its standard error (Gerbing and Anderson, 1988). Discriminant validity (i.e. the degree to which measures of two constructs are empirically distinct) (Nunnally and Bernstein 1994) was demonstrated, since the average variance extracted for each construct, was greater than the squared correlation between that construct and any other construct (Fornell and Larcker, 1981).

Nomological validity. Nomological validity refers to the degree to which a construct behaves as expected within a system of related constructs (Shimp and Sharma, 1987). Since motivations are positive antecedents, we expect them to be negatively correlated with impediments which are negative antecedents. We therefore correlated the ORM dimensions to 'product attachment' which we measured by adapting Guillard and Pinson's (2012) Tendency to Keep Everything measurement scale; as well as 'perceived risk associated with online resale website' and 'financial risk', by developing items based on Manchanda and Chu's (2013) and Xinyan and Xingjing's (2010) studies on online resale impediments. These items were measured on 10point Likert scales. The correlations between motivations and impediments ranged between -0.453 and .055 . Besides, fourteen correlations were significantly negative and four were non-significant, which provides preliminary evidence for the nomological validity of the ORM scale. Studies 2 and 3 provide further support for nomological validity.

\subsection{Discussion}

Through Study 1, a scale for measuring motivations to resell products online was developed and showed robust psychometric properties. Six motivational dimensions were identified, namely protester, economic, generative, recreational, practical and social.

While previous literature mostly emphasized the online channel as being used for economic and generative purposes (e.g. Chu and Liao, 2007, 2010; Murphy and Liao, 2013), some more counter-intuitive motivations i.e. social, recreational come also into play. This is an interesting finding especially given that most literature on computer-mediated channels and communications was originally depicted as lacking social interaction, reciprocity, pleasurable experiences and interactivity (Barlow et al., 2004). While this certainly holds true in a non-interactive setting such as the pre-Web 2.0 era studied by Barlow et al. (2004), Web 2.0 and social media upon which second-hand websites capitalize, clearly change that, notably by introducing interactivity and gamification (Insley and Nunan, 2014). Furthermore, the finding of a recreational motive to online resale prompts the potential role of the flow and play constructs.

\section{Study 2: Scale Validation}

\subsection{Conceptual Framework}

Perugini and Bagozzi's (2001) model of goal-directed behaviour (MGB) emphasized a volitional link between motivations and behaviours. Actually, motivations are pertinent precursors to behaviour (Shaw et al., 2007). Indeed, motivations constitute the completion of the process which translates expected outcomes into 
fulfilled outcomes by directing the fulfilment of the outcome to specific actions (Shaw et al., 2007). This process gives way to the realization of the behaviour on a conative level (Bagozzi and Warshaw, 1990; Bagozzi, 1992). In accordance with our expectancy theory framework for motivations, when the need to dispose of a product emerges, the consumer evaluates perceived outcomes of various disposition channels including online resale - and then emits the desire to expend energy and efforts (motivations) to fulfill the disposition action that maximizes expected outcomes. The greater the expectations of desirable outcomes related to online resale compared to other disposition channels, the greater the motivation to do so, and the greater the likelihood of online reselling occurring at more frequent intervals. Thus: H1: The online resale motivation scale positively relates to online resale frequency

\subsection{Methodology}

Design and procedures. Members $(\mathrm{n}=1,119)$ of a Canadian online consumer panel were contacted and 437 answered the survey, representing a $43 \%$ response rate. Women made up $38 \%$ of the sample and the average age was 46 years; $5 \%$ were $15-24$ years old, $43 \%$ were $25-44,43 \%$ were $45-64$, and $9 \%$ were 65 and over; $62 \%$ had a college or university degree.

Measures. The dependent variable was online resale frequency. Participants were asked a question about the frequency at which they sold second-hand items online (over the past twelve months), on a ten-point scale where $1=$ 'Never' and $10=$ 'Very often'. The same measure was used in study 3 . Gender and age were added as control variables because, younger consumers and males were more likely to use new technologies (Venkatesh et al., 2012). Age is a ratio-scaled variable, which has a real zero value. It is therefore of interest to verify whether these patterns hold in the case of resale website use.

Fit, validity and reliability. An EFA confirmed the six-factor model for ORM. A CFA confirmed good fit $\left(\chi^{2}(155)=296.39, \mathrm{p}=0.00, \mathrm{NFI}=.98 ; \mathrm{NNFI}=.99 ; \mathrm{CFI}=.99 ; \mathrm{IFI}=.99 ; \mathrm{RFI}=.98 ; \mathrm{RMSEA}=0.046\right.$; RMSR $=.044$, GFI $=.94$; AGFI $=.91$ ). Table 1 reports the results of the CFA (column 3 ). All factor loadings were highly significant ( $\mathrm{p}$.001), demonstrating dimensionality (Gerbing and Anderson, 1988). All items loaded significantly on their corresponding latent factor and all AVEs were above .50, supporting convergent validity (Fornell and Larcker, 1981). High Cronbach's alphas and construct reliabilities demonstrated internal consistency. The average variance extracted (AVE) for each construct is greater than the squared correlation between that construct and any other construct (Fornell and Larcker, 1981). This was the case for all constructs, therefore discriminant validity is established. (see Table 2). We re-tested the correlation between ORM and the same impediments with the same measurement properties, as in study 1. ORM dimensions displayed fifteen significantly negative and three non-significant relationships with impediments. Correlations ranged from .468 to .038 , providing further evidence of nomological validity.

Table 2. Correlation and descriptive statistics - Study $2(n=437)$

\begin{tabular}{|l|c|c|c|c|c|c|}
\hline & $\mathbf{1}$ & $\mathbf{2}$ & $\mathbf{3}$ & $\mathbf{4}$ & $\mathbf{5}$ & $\mathbf{6}$ \\
\hline 1. Protester & 1.00 & & & & & \\
\hline 2. Economic & .41 & 1.00 & & & & \\
\hline 3. Generative & .40 & .33 & 1.00 & & & \\
\hline 4. Recreational & .53 & .42 & .29 & 1.00 & & \\
\hline 5. Practical & .28 & .38 & .57 & .23 & 1.00 & \\
\hline 6. Social & .59 & .35 & .61 & .55 & .45 & 1.00 \\
\hline Mean & 4.72 & 5.37 & 7.07 & 4.10 & 7.39 & 5.84 \\
\hline Standard deviation & 2.79 & 2.72 & 2.47 & 2.70 & 2.40 & 2.66 \\
\hline Average variance extracted (AVE) & .74 & .67 & .78 & .83 & .84 & .83 \\
\hline Highest shared variance & .35 & .18 & .37 & .30 & .32 & .37 \\
\hline
\end{tabular}

\subsection{Analysis and Results}

A regression analysis showed that ORM positively and significantly impact online resale frequency $(\beta=.333, \mathrm{t}=7.358, \mathrm{p}<.001)$, which validates $\mathrm{H1}$. A hierarchical regression analysis was conducted to test the detailed impact of each ORM dimensions on online resale frequency. Table 3 shows the findings of the regression analysis. There is no interaction effect between age and gender but males and younger consumers are more likely to resell frequently online. 
Ertz, M., Durif, F. and Arcand, M., 2016. Business in the Hands of Consumers: A Scale for Measuring Online Resale Motivations. Expert Journal of Marketing, 4(2), pp. 60-76.

Table 3. Hierarchical Regression Analysis (Dependent variable: Online Resale Frequency Index) $(n=437)$

\begin{tabular}{|c|c|c|c|c|c|c|}
\hline & \multicolumn{3}{|c|}{ Step 1} & \multicolumn{3}{|c|}{ Step 2} \\
\hline Variables & $\beta^{\mathrm{a}}$ & $t$-value & $p$-value & $\boldsymbol{\beta}^{a}$ & $t$-value & $p$-value \\
\hline \multicolumn{7}{|l|}{ Controls } \\
\hline Age & -.253 & $-5.406 * * *$ & .000 & -.239 & $-5.427 * * *$ & .000 \\
\hline Sex & -.095 & $-2.022 *$ & .044 & -.125 & $-2.807 * *$ & .005 \\
\hline Age * Sex & .041 & .022 & .826 & .041 & .234 & .815 \\
\hline \multicolumn{7}{|c|}{ Main Effects } \\
\hline Protester & & & & .175 & $4.057 * * *$ & .000 \\
\hline Economic & & & & .159 & $3.635 * * *$ & .000 \\
\hline Generative & & & & .107 & $2.466^{*}$ & .014 \\
\hline Recreational & & & & .200 & $4.618 * * *$ & .000 \\
\hline Practical & & & & .138 & $3.184 * *$ & .002 \\
\hline Social & & & & .125 & $2.892 * *$ & .004 \\
\hline$R^{2}$ & \multicolumn{3}{|c|}{.066} & \multicolumn{3}{|c|}{.207} \\
\hline$F$ & \multicolumn{3}{|c|}{$13.938 * * *$} & \multicolumn{3}{|c|}{$15.392 * * *$} \\
\hline$\Delta R^{2}$ & & & & \multicolumn{3}{|c|}{.141} \\
\hline$\Delta F$ & & & & \multicolumn{3}{|c|}{$12.7 * * *$} \\
\hline
\end{tabular}

Note: ${ }^{a}$ Standardized coefficients. $* p<.05 ; * * p<.01 ; * * * p<.001$.

Further, the protester, economic, generative, recreational, practical and social motivations all positively and significantly related to online resale frequency. These results further validate H1. A structural equation model supported those findings exhibiting excellent fit $\left(\chi_{(169)}^{2}=303.090, \mathrm{NFI}=.964, \mathrm{NNFI}=.980\right.$, $\mathrm{CFI}=.984, \mathrm{IFI}=.984, \mathrm{SRMR}=.042, \mathrm{RMSEA}=.043$ (Confidence Interval: .035; .050)), as well as directional and significant paths at the scale-level $(b=.228 \mathrm{p}<.001)$, and on the dimension-level. Interestingly, when inserting the impediments measurement scale in the model, the direct effect of ORM on Online Resale Frequency increases strongly $(\beta=.839, \mathrm{t}=5.501, \mathrm{p}<.001)$ and there is a significantly negative interaction between ORM and online resale impediments, so that the latter dampens the positive relationship between ORM and online resale frequency $(\beta=-.555, \mathrm{t}=-3.394, \mathrm{p}<.001)$. In accordance with the valence framework (Peter and Tarpey, 1975; Bilkey, 1953), this suggests that consumers perceive both positive and negative attributes to online resale and, accordingly, make decisions to maximize the net valence resulting from positive and negative antecedents of the decision (Kim et al., 2008). For consumers to actually enact the online resale behavior, motivations need therefore to be higher in order to overcome the inhibitory effect of impediments.

Table 4. Main effects of dimensions (standardized beta values) $(n=437)$

\begin{tabular}{|l|c|}
\hline & Estimate \\
\hline Protester $\rightarrow$ ORF & $.176^{* * *}$ \\
\hline Economic $\rightarrow$ ORF & $.184^{* * *}$ \\
\hline Generative $\rightarrow$ ORF & $.098^{* * *}$ \\
\hline Recreational $\rightarrow$ ORF & $.206 * * *$ \\
\hline Practical $\rightarrow$ ORF & $.118^{* * *}$ \\
\hline Social $\rightarrow$ ORF & $.115^{* * *}$ \\
\hline
\end{tabular}

Note: $* * * \mathrm{p}<.001$, ORF: Online Resale Frequency.

\subsection{Online Reseller Segments}

To evaluate the practical use of the proposed ORM scale, a two-stage Classification procedure was undertaken, using both hierarchical and non-hierarchical cross-validation (Hair et al., 2006; Guiot and Roux (2010). The first stage subjected the six dimensions of ORM to a Ward's hierarchical classification algorithm and which uses the squared Euclidean distance in order to compute cluster centroids. Several solutions were considered in order to determine the optimal number of clusters (Hair et al., 2006). By examining the outputs, namely the dendogram, the vertical icicle diagram and the agglomeration schedule, a three-cluster solution was chosen. The second stage involved a K-means dynamic clustering analysis with the cluster centers from the hierarchical classification. Table 5 summarizes the means that correspond to the dimensions of ORM and indicates the final allocation of the subjects to the three clusters $(\mathrm{N} 1=118, \mathrm{~N} 2=189$, N3=130). Multiple ANOVA analyses were then subsequently used in order to indicate significant differences across the three clusters. The $F$-values vary from 98.93 to 262.80 . Finally, post hoc Tukey or Dunnet tests confirmed that the mean score differences among the three clusters for all variables are significant. 
Ertz, M., Durif, F. and Arcand, M., 2016. Business in the Hands of Consumers: A Scale for Measuring Online Resale Motivations. Expert Journal of Marketing, 4(2), pp. 60-76.

Table 5. Results of non-hierarchical cluster analysis and validation.

\begin{tabular}{|c|c|c|c|c|c|c|c|c|}
\hline \multirow[b]{2}{*}{ Constructs } & \multicolumn{4}{|c|}{ Study $1(n=437)$} & \multicolumn{4}{|c|}{ Study $2(n=205)$} \\
\hline & $\begin{array}{c}\text { Cluster 1 } \\
\text { Sporadic } \\
\text { experiencers }\end{array}$ & $\begin{array}{c}\text { Cluster } 2 \\
\text { Pragmatics }\end{array}$ & $\begin{array}{l}\text { Cluster } 3 \\
\text { Online } \\
\text { aficionados }\end{array}$ & $\begin{array}{l}\text { Value of F } \\
\text { (or of Chi' } \\
\text { in italic) }\end{array}$ & $\begin{array}{c}\text { Cluster 1 } \\
\text { Sporadic } \\
\text { experiencers }\end{array}$ & $\begin{array}{c}\text { Cluster } 2 \\
\text { Pragmatics }\end{array}$ & $\begin{array}{l}\text { Cluster } 3 \\
\text { Online } \\
\text { aficionados }\end{array}$ & $\begin{array}{l}\text { Value of F } \\
\text { (or of } \mathrm{Chi}^{2} \\
\text { in italic) }\end{array}$ \\
\hline \multicolumn{9}{|c|}{ Online Resale Motivations } \\
\hline Protester & $\begin{array}{c}2.74 \\
(2.75)\end{array}$ & $\begin{array}{c}4.58 \\
(4.58)\end{array}$ & $\begin{array}{c}7.63 \\
(7.63)\end{array}$ & $201.19 * * *$ & $\begin{array}{c}2.84 \\
(3.05)\end{array}$ & $\begin{array}{c}4.68 \\
(4.86)\end{array}$ & $\begin{array}{c}7.61 \\
(7.85)\end{array}$ & $95.98 * * *$ \\
\hline Economic & $\begin{array}{c}3.84 \\
(3.84)\end{array}$ & $\begin{array}{c}4.77 \\
(4.77)\end{array}$ & $\begin{array}{c}7.69 \\
(7.64)\end{array}$ & $98.93 * * *$ & $\begin{array}{c}4.26 \\
(4.21)\end{array}$ & $\begin{array}{c}4.68 \\
(5.36)\end{array}$ & $\begin{array}{c}7.61 \\
(8.00)\end{array}$ & $52.34 * * *$ \\
\hline Generative & $\begin{array}{c}4.25 \\
(4.25)\end{array}$ & $\begin{array}{c}7.68 \\
(7.69)\end{array}$ & $\begin{array}{c}8.73 \\
(8.73)\end{array}$ & $227.50 * * *$ & $\begin{array}{c}4.02 \\
(4.42)\end{array}$ & $\begin{array}{c}7.37 \\
(7.47)\end{array}$ & $\begin{array}{c}8.51 \\
(8.69)\end{array}$ & $104.64 * * *$ \\
\hline Recreational & $\begin{array}{c}2.56 \\
(2.56)\end{array}$ & $\begin{array}{c}3.50 \\
(3.50)\end{array}$ & $\begin{array}{c}6.78 \\
(6.78)\end{array}$ & $162.84 * * *$ & $\begin{array}{c}3.00 \\
(3.10)\end{array}$ & $\begin{array}{c}3.76 \\
(4.03)\end{array}$ & $\begin{array}{c}6.87 \\
(6.93)\end{array}$ & $69.01 * * *$ \\
\hline Pragmatic & $\begin{array}{c}4.89 \\
(4.89)\end{array}$ & $\begin{array}{c}7.57 \\
(7.57)\end{array}$ & $\begin{array}{c}8.60 \\
(8.60)\end{array}$ & $126.73 * * *$ & $\begin{array}{c}5.08 \\
(5.22)\end{array}$ & $\begin{array}{c}7.60 \\
(7.81)\end{array}$ & $\begin{array}{c}8.71 \\
(8.85)\end{array}$ & $65.28 * * *$ \\
\hline Social & $\begin{array}{c}2.99 \\
(3.00)\end{array}$ & $\begin{array}{c}5.99 \\
(5.99)\end{array}$ & $\begin{array}{c}8.21 \\
(8.21)\end{array}$ & $262.80 * * *$ & $\begin{array}{c}3.49 \\
(3.71)\end{array}$ & $\begin{array}{c}6.14 \\
(6.34)\end{array}$ & $\begin{array}{c}8.14 \\
(8.35)\end{array}$ & $107.86^{* * *}$ \\
\hline \multicolumn{9}{|c|}{ Descriptive characteristics of clusters } \\
\hline Size of cluster $(\mathrm{N})$ & 118 & 189 & 130 & & 48 & 87 & 70 & \\
\hline Size as $\%$ & $27 \%$ & $43 \%$ & $30 \%$ & & $23 \%$ & $42 \%$ & $34 \%$ & \\
\hline $\begin{array}{l}\text { Online Resale } \\
\text { Frequency }\end{array}$ & 2.97 & 3.61 & 4.93 & $28.24 * * *$ & 3.18 & 3.95 & 5.18 & $12.63 * * *$ \\
\hline $\begin{array}{l}\text { Planned Resale } \\
\text { Intentions }\end{array}$ & & & & & 5.42 & 5.72 & 6.20 & $3.89 *$ \\
\hline $\begin{array}{l}\text { Number of } \\
\text { products resold (+ } \\
\text { than } 10) \text { as a } \%\end{array}$ & 8.50 & 11.1 & 12.3 & $13.35^{*}$ & 2.1 & 13.8 & 12.9 & 10.99 \\
\hline $\begin{array}{l}\text { Perception of } \\
\text { amount of money } \\
\text { earned by } \\
\text { reselling products } \\
\text { online }\end{array}$ & 3.02 & 4.52 & 6.07 & $36.64 * * *$ & 3.23 & 4.80 & 6.23 & $16.24 * * *$ \\
\hline $\begin{array}{l}\text { Past Resale } \\
\text { Experience } \\
\text { (online or } \\
\text { offline) }\end{array}$ & 2.13 & 2.18 & 2.31 & $6.41 * *$ & 2.15 & 2.30 & 2.70 & $7.17 * *$ \\
\hline $\begin{array}{l}\text { Past second-hand } \\
\text { purchase (online } \\
\text { or offline) })^{\mathrm{a}}\end{array}$ & 2.25 & 2.34 & 2.64 & $6.36 * *$ & 2.15 & 2.28 & 2.31 & 2.24 \\
\hline $\begin{array}{l}\text { Amount of money } \\
\text { earned by } \\
\text { reselling products } \\
\text { online (less than } \\
\text { CAD 250) as a \% }\end{array}$ & 61.4 & 42.6 & 53.1 & $17.19 *$ & 65.6 & 58.4 & 39.7 & $16.01 *$ \\
\hline $\begin{array}{l}\text { Amount of money } \\
\text { earned by } \\
\text { reselling product } \\
\text { online (CAD } 250 \\
\text { to CAD 750) as a } \\
\%\end{array}$ & 31.6 & 46.3 & 29.7 & & 28.2 & 32.5 & 46.6 & \\
\hline $\begin{array}{l}\text { Amount of money } \\
\text { earned by } \\
\text { reselling product } \\
\text { online (CAD } 751 \\
\text { to CAD 1000) }\end{array}$ & 7.0 & 11.1 & 17.2 & & 6.2 & 9.1 & 13.7 & \\
\hline $\begin{array}{l}\text { Online reselling } \\
\text { of printers as a } \%\end{array}$ & 1.7 & 4.8 & 7.7 & $21.35 *$ & 4.2 & 5.7 & 10.0 & $26.09 *$ \\
\hline $\begin{array}{l}\text { Online reselling } \\
\text { of video cameras } \\
\text { as a } \%\end{array}$ & 4.2 & 1.6 & 6.9 & $23.00^{*}$ & 7.1 & 3.4 & 8.3 & 18.62 \\
\hline $\begin{array}{l}\text { Online reselling } \\
\text { of decoration } \\
\text { objects as a \% }\end{array}$ & 5.1 & 9.5 & 13.8 & $22.41 *$ & 8.3 & 10.3 & 10.0 & 19.84 \\
\hline
\end{tabular}


Ertz, M., Durif, F. and Arcand, M., 2016. Business in the Hands of Consumers: A Scale for Measuring Online Resale Motivations. Expert Journal of Marketing, 4(2), pp. 60-76.

\begin{tabular}{|c|c|c|c|c|c|c|c|c|}
\hline $\begin{array}{l}\text { Online reselling } \\
\text { of mp3 players as } \\
\text { a } \%\end{array}$ & 1.6 & 3.4 & 5.4 & $30.97 *$ & 3.4 & 5.7 & 6.3 & $24.98^{*}$ \\
\hline $\begin{array}{l}\text { Online reselling } \\
\text { of furniture as a } \\
\%\end{array}$ & 16.1 & 26.5 & 25.4 & $26.37 *$ & 18.8 & 27.6 & 25.7 & 18.36 \\
\hline $\begin{array}{l}\text { Online reselling } \\
\text { of sport articles as } \\
\text { a \% }\end{array}$ & 8.5 & 9.5 & 14.6 & $22.36^{*}$ & 10.4 & 10.3 & 17.1 & 19.62 \\
\hline $\begin{array}{l}\text { Online reselling } \\
\text { of cars as a } \%\end{array}$ & 6.8 & 6.9 & 17.7 & $22.77 *$ & 4.2 & 9.2 & 21.4 & $20.64 *$ \\
\hline $\begin{array}{l}\text { Online reselling } \\
\text { via websites } \\
\text { selling second- } \\
\text { hand / auctions } \\
\text { websites }\end{array}$ & 2.59 & 3.42 & 4.80 & $13.90 * * *$ & 2.83 & 3.97 & 5.00 & $67.42 * *$ \\
\hline $\begin{array}{l}\text { Online reselling } \\
\text { via classified ads } \\
\text { websites }\end{array}$ & 4.43 & 5.58 & 6.62 & $11.25 * * *$ & 4.60 & 5.82 & 6.89 & $74.61 * *$ \\
\hline \multicolumn{9}{|c|}{ Socio-demographic indicators } \\
\hline $\begin{array}{l}\text { Less than } \\
\text { CAD20k }(\%)\end{array}$ & 15.6 & 18.6 & 13.8 & 4.16 & 15.7 & 11.5 & 16.7 & 2.32 \\
\hline $\begin{array}{l}\text { CAD20k- } \\
\text { CAD59k }(\%)\end{array}$ & 43.2 & 43.9 & 49.2 & & 50.0 & 44.8 & 47.9 & \\
\hline $\begin{array}{l}\text { CAD60k- } \\
\text { CAD99k (\%) }\end{array}$ & 24.6 & 27.0 & 26.2 & & 21.4 & 25.3 & 22.9 & \\
\hline CAD100k + (\%) & 13.6 & 15.3 & 9.2 & & 12.9 & 18.4 & 12.5 & \\
\hline No education & 5.9 & 3.7 & 2.3 & 10.07 & 1.4 & 3.4 & 10.4 & 10.76 \\
\hline $\begin{array}{l}\text { Primary / } \\
\text { Secondary }\end{array}$ & 38.1 & 28.0 & 40.8 & & 35.7 & 28.7 & 39.6 & \\
\hline $\begin{array}{l}\text { Attended } \\
\text { university }\end{array}$ & 25.4 & 33.9 & 31.5 & & 38.6 & 32.2 & 22.9 & \\
\hline University degree & 30.5 & 34.4 & 25.4 & & 24.3 & 35.6 & 27.1 & \\
\hline
\end{tabular}

Note: * Significant at .05; ** Significant at .01; *** Significant at $.001 .^{\text {a }}$ measured on a scale of 1 "never" to 4 "very often".

As shown in Table 5, the three reseller segments, characterized by their different score levels on the various types of motivations, were labelled "sporadic experiencers", "pragmatics", and "online aficionados". On the basis of these clusters, the typology can predict differences in the number of products resold online, the amount of money earned by reselling products online, and other behaviours linked to online resale.

Sporadic experiencers are characterized as being the least involved in online reselling. They exhibit a weaker proportion of more than 10 products sold online $(8.5 \%)$ and of amounts of money earned by reselling products online superior to CAD $750(7.0 \%)$. They reveal the lowest scores for the various motivations and are characterized by a weak propensity to resell frequently online. In terms of their experience with the secondhand market either online or offline, they exhibit the lowest levels of past resale experience and past secondhand purchase experience. More or less equally divided among men and women, these sporadic experiencers do not exhibit any particular socio-demographic aspect.

Representing $43 \%$ of the total sample, the pragmatics score high on the pragmatic and generative dimensions. Characterized by their strong propensity to resell furniture online (26.5\%) and to earn medium level of earnings online (46.3\% between CAD 250 and CAD 750 versus $35.7 \%$ for the whole sample), these consumers reflect moderate scores on almost all variables, appearing therefore as medium online resellers. Basically, they refer to those consumers who mostly perceive the web as a fast and easy way to dispose of goods (Lemaitre and de Barnier, 2015), and who are mostly interested in the pragmatic and generative aspects inherent to online resale. Finally, the online aficionados (30\% of total sample) score higher on virtually all dimensions, especially generative, pragmatic, and social. They resell more often online, more and all kinds of products, and earn therefore more money than sporadic experiencers and pragmatics. Basically, they are more likely to be or to become professional resellers (Chu and Liao, 2007) who use the Internet as an outlet to resell recurrently several units of identical products or buy products in order to resell them online.

\subsection{Discussion}

This study provides additional evidence of the validity of the ORM scale The study confirms that motivation to perform a behaviour significantly impacts the frequency of such behaviour. Importantly, each type of motive i.e. expected outcome, significantly and directionally increases the frequency at which 
consumers resell products online. By considering ORM, three types of online-reseller profiles emerge, namely sporadic experiencers, pragmatics and online aficionados. The reselling behaviour of these reseller segments tends to be relatively well related to their motivational level. The ORM-based typology also appears as a consistent predictor of online resales across many possible combinations of products and across the two main online resale channels i.e. second-hand / auctions websites and classified ads websites.

\section{Study 3: Scale Validation}

\subsection{Conceptual Framework}

In topical literature, reselling is generally prompted by a consumer desire to dispose of an unwanted or unneeded product - intended for self-use - after having acquired it but not prior to purchase, which refers to the notion of unplanned resale (Boyd and McConocha, 1996; Hanson, 1980; Harrell and McConocha, 1992; Jacoby et al., 1977; Paden and Stell, 2005). In early resale literature, some resellers were identified as planning item resales prior to purchase (Belk et al., 1988; Prus, 1984; Sherry, 1990). Consumers' planning to resale a product prior to having purchased that product refers to planned resale (Boyd and McConocha, 1996; Harrell and McConocha, 1992; Prus, 1984). Behaviour of this nature was not, however, widespread among consumers. The Web may have increased planned resale tendencies (Chu and Liao, 2007; Murphy and Liao, 2013; Liao and Chu, 2013; Nissanoff, 2006). Chu and Liao (2010) invoked mental accounting theory to explain that reselling may indeed be prompted by consumer acknowledgment - upstream of a new or second-hand purchase - of the possibility or intention of reselling a given product after having owned it for a certain period of time.

Similarly to mental accounting theory, which posits that consumers consider money as a fungible asset (Kahneman et al., 1991; Thaler, 1980), the Internet and C2C outlets have enabled consumers to no longer consider goods as unrecoverable, unmovable or sunk costs, but as liquid assets or alternative cash accounts (Liao and Chu, 2013; Zhang, 2015). Planned resale intentions are therefore defined as "the condition where, prior to purchase, consumers consider that they have the intention to resell the target product after possessing it for a period of time" (Chu and Liao, 2007, p.7). Intentions such as these may relate to one or other of a situation in which the consumer uses the product (e.g. resale after temporary ownership) or does not use the product (e.g, resale of unnecessary purchase) (Chu and Liao, 2007, p. 7).

Although never tested before, PRI may be positively related to ORM. Consumers who purchase goods with the intention of reselling them at a future timeframe may therefore have higher ORM. This is because they deliberately expect positive outcomes from their future online resale (see Figure 1) and therefore:

H2: Planned Resale Intentions positively impacts online resale motivations.

Similarly, since the web has increased the tendency of consumers to develop PRI toward products that they might purchase, it may be reasonably hypothesized that PRI increase the occurrence of online resale. We thus examine the new testing of PRI effect on online resale frequency:

H3: Planned Resale Intentions influence positively online resale frequency.

In addition to a direct effect, we hypothesize that PRI positively influence through the intermediary of ORM. Therefore, we investigate the testing of the mediating role of ORM upon online resale frequency:

H4: Online resale motivations mediate the relationship between planned resale intentions and online resale frequency.

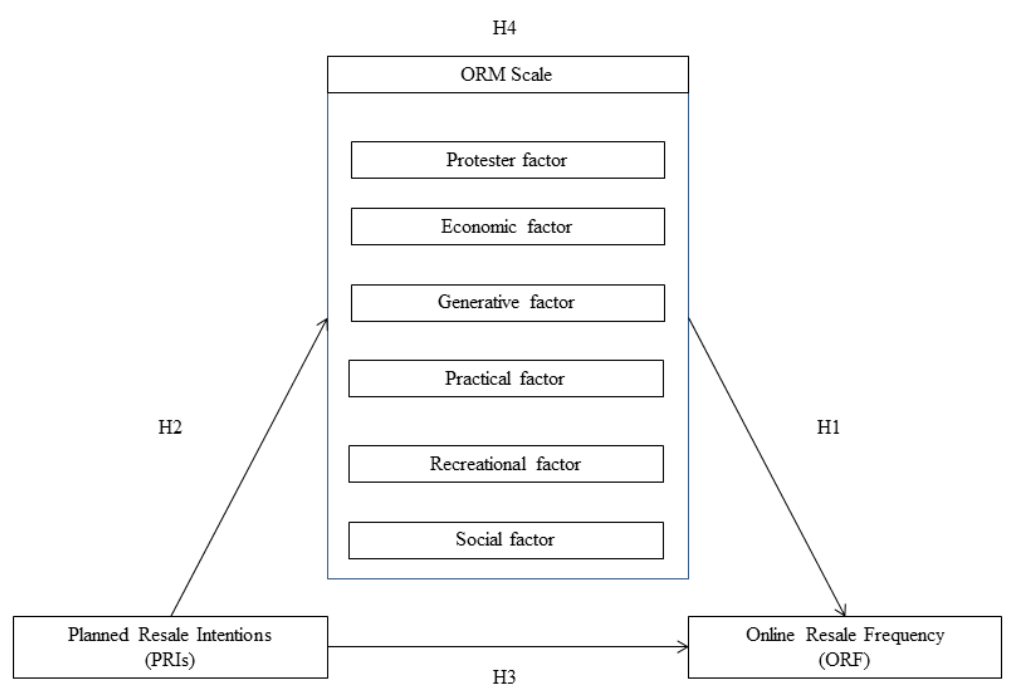

Figure 1. Conceptual model 


\subsection{Methodology}

Design and procedure. Members $(\mathrm{n}=1,001)$ of a Canadian online panel were contacted and 205 answered the survey (20\% response rate). Women constituted $37 \%$ of the sample and the average age was 43 years; $7 \%$ were $15-24$ years old, $55 \%$ were $25-44,32 \%$ were $45-64$, and $6 \%$ were 65 and over; $70 \%$ had a college or university degree.

Measures. To assess PRIs, respondents were asked to indicate whether they had ever held PRI in the past based on a four-point scale ( 1 = "never", 2 = "rarely", 3 = "often" and 4 = "always"). No specific mention was made as to the type of channel on which respondents planned to do their resale. The four points cover the whole spectrum of possible intentions that participants could have had.

Measure validation. An EFA confirmed the six-factor model of ORM. The CFA model yielded good fit $\left(\chi^{2}(155)=313.39, \mathrm{p}=0.00, \mathrm{NFI}=.96 ; \mathrm{NNFI}=.98 ; \mathrm{CFI}=.98 ; \mathrm{IFI}=.98 ; \mathrm{RFI}=.95 ; \mathrm{RMSEA}=0.071\right.$; RMSR $=.060$, GFI $=.93$, AGFI $=.90)$, dimensionality, convergent validity, reliability and discriminant validity (Tables 1 and 6). We re-tested the correlation between ORM and online resale impediments with the same measurement properties, as in study 1 and 2. ORM dimensions displayed fourteen significantly negative and four non-significant relationships with impediments with correlations ranging from -.460 to .064, providing evidence of nomological validity.

Table 6. Correlation and descriptive statistics - Study $3(n=205)$

\begin{tabular}{|l|c|c|c|c|c|c|}
\hline & 1 & 2 & 3 & 4 & 5 & 6 \\
\hline 1. Protester & 1.00 & & & & & \\
\hline 2. Economic & .42 & 1.00 & & & & \\
\hline 3. Generative & .39 & .42 & 1.00 & & & \\
\hline 4. Recreational & .51 & .45 & .25 & 1.00 & & \\
\hline 5. Practical & .27 & .43 & .61 & .16 & 1.00 & \\
\hline 6. Social & .56 & .43 & .66 & .51 & .52 & 1.00 \\
\hline Mean & 4.97 & 5.84 & 6.98 & 4.52 & 7.56 & 6.20 \\
\hline Standard deviation & 2.75 & 2.56 & 2.40 & 2.65 & 2.21 & 2.42 \\
\hline Average Variance Extracted (AVE) & .81 & .66 & .80 & .84 & .85 & .80 \\
\hline Highest Shared Variance & .31 & .20 & .44 & .26 & .37 & .44 \\
\hline
\end{tabular}

\subsection{Analysis and Results}

We conducted a regression-based mediation analysis using bootstrapping on 1000 resamples, at a 95\% confidence level (Hayes, 2013). For ease of comparison, we report standardized coefficients. The results obtained replicate those found in study 2 . There is a significant and positive relationship between ORM and online resale frequency (see Table 7), lending additional support to H1. When inserting the impediments measurement scale in the model, the direct effect of ORM on Online Resale Frequency increases again strongly $(\beta=.801, t=3.680, p<.001)$ and there is a significantly negative interaction between ORM and online resale impediments, so that the latter dampens the positive relationship between ORM and online resale frequency $(\beta=-.619, \mathrm{t}=-2.617, \mathrm{p}<.001)$. This may provide further evidence for the fact that for consumers to actually enact the online resale behavior, motivations need to be higher to overcome the inhibitory effect of impediments.

Furthermore, the effect of PRI on ORM is directional and significant, providing support for $\mathrm{H} 2$. Interestingly, the total effect of PRI on online resale frequency, while significant with regards to its total effect $(\beta=.1455, t=2.1228, \mathrm{p}=.0020)$, is not significant in light of its direct effect $(\beta=.0849, t=1.2657, \mathrm{p}=$ $.2071)$, indicating full mediation. It is by means of the significant indirect effect via ORM $(\beta=.0606)$, that the effect of PRI on online resale frequency becomes significant.

The bootstrapping method does not provide a $p$-value in order to assess whether an indirect effect is significant but it computes a bias corrected confidence interval and a percentile confidence interval. An effect is significant when "zero" is not included in either confidence interval (Hayes, 2013). In our case, both the bias corrected confidence interval (LCL: .0211; UCL: .1281) and the percentile confidence interval (LCL: .0175; UCL: .1197) do not comprise zero, which indicates that the indirect effect via ORM is significant.

ORM render the previously non-significant positive relationship between PRI and online resale frequency significant. In other words, consumers' intentions to resell a product prior to its purchase in a future timeframe, does not lead them to resell online more frequently. But it is through heightened motivations to resell online that they tend to increase the frequency of their online resales. Through the multi-faceted positive outcomes that they perceive when reselling online, consumers tend to opt more often for online resale. Hence, $\mathrm{H} 3$ is not supported whereas H4 is supported. Some dimensions contribute more than others to the significance 
of this relationship. Using bootstrapping again, a mediation analysis was conducted with each dimension of the ORM scale as the mediator. The findings revealed that the economic, recreational and practical dimensions account for the significance of the mediating role of ORM upon online resale frequency. Conversely, the protester, generative and social dimensions do not contribute to significantly mediate that relationship (Table 7).

Table 7. Bootstrapping Mediation Analysis (Dependent variable: Online Resale Frequency) - Study 3 ( $n=205)$

\begin{tabular}{|c|c|c|c|c|}
\hline Variables & $\boldsymbol{\beta}^{a}$ & $t$-value & $p$-value & $\begin{array}{c}\text { Bias corrected } \\
\text { Confidence } \\
\text { Interval } \\
\end{array}$ \\
\hline \multicolumn{5}{|c|}{ Overall mediation model } \\
\hline $\mathrm{ORM} \rightarrow \mathrm{ORF}(\mathrm{H} 1)$ & .3195 & 4.3693 & .0000 & \\
\hline PRI $\rightarrow$ ORM (H2) & .1896 & 2.9876 & .040 & \\
\hline PRI $\rightarrow$ ORF (total effect) & .1455 & 2.1228 & .002 & \\
\hline PRI $\rightarrow$ ORF (direct effect) & .0849 & 1.2657 & .006 & \\
\hline PRI $\rightarrow$ ORF (indirect effect) & .0606 & & & $(.0211 ; .1281)$ \\
\hline$R^{2}$ & \multicolumn{4}{|c|}{.1468} \\
\hline Adjusted- $R^{2}$ & \multicolumn{4}{|c|}{$.1254(\mathrm{p}<.001)$} \\
\hline \multicolumn{5}{|c|}{ Protester dimension mediated model } \\
\hline PROTESTER $\rightarrow$ ORF & .2576 & 3.6078 & .0004 & \\
\hline PRI $\rightarrow$ PROTESTER & .0996 & 1.5107 & .1324 & \\
\hline PRI $\rightarrow$ ORF (total effect) & .1455 & 2.1228 & .0350 & \\
\hline PRI $\rightarrow$ ORF (direct effect) & .1198 & 1.7901 & .0750 & \\
\hline PRI $\rightarrow$ ORF (indirect effect) & .0256 & & & $(-.0082 ; .0765)$ \\
\hline$R^{2}$ & \multicolumn{4}{|c|}{.1224} \\
\hline Adjusted- $R^{2}$ & \multicolumn{4}{|c|}{$.1003(\mathrm{p}<.001)$} \\
\hline \multicolumn{5}{|c|}{ Economic dimension mediated model } \\
\hline ECONOMIC $\rightarrow$ ORF & .2913 & 3.8236 & .0002 & \\
\hline PRI $\rightarrow$ ECONOMIC & .2007 & 3.2622 & .0013 & \\
\hline PRI $\rightarrow$ ORF (total effect) & .1455 & 2.1228 & .0350 & \\
\hline PRI $\rightarrow$ ORF (direct effect) & .0870 & 1.2783 & .2026 & \\
\hline PRI $\rightarrow$ ORF (indirect effect) & .0585 & & & $(.0233 ; .1140)$ \\
\hline$R^{2}$ & \multicolumn{4}{|c|}{.1290} \\
\hline Adjusted- $R^{2}$ & \multicolumn{4}{|c|}{$.1071(\mathrm{p}<.001)$} \\
\hline \multicolumn{5}{|c|}{ Generative dimension mediated model } \\
\hline GENERATIVE $\rightarrow$ ORF & .3018 & 4.2326 & .0000 & \\
\hline PRI $\rightarrow$ GENERATIVE & .0626 & .9591 & .3387 & \\
\hline PRI $\rightarrow$ ORF (total effect) & .1455 & 2.1228 & .0350 & \\
\hline PRI $\rightarrow$ ORF (direct effect) & .1266 & 1.9193 & .0564 & \\
\hline PRI $\rightarrow$ ORF (indirect effect) & .0189 & & & $(-.0158 ; .0723)$ \\
\hline$R^{2}$ & \multicolumn{4}{|c|}{.1422} \\
\hline Adjusted- $R^{2}$ & \multicolumn{4}{|c|}{$.1206(\mathrm{p}<.001)$} \\
\hline \multicolumn{5}{|c|}{ Recreational dimension mediated model } \\
\hline RECREATIONAL $\rightarrow$ ORF & .2090 & 2.8553 & .0048 & \\
\hline PRI $\rightarrow$ RECREATIONAL & .1994 & 3.0649 & .0025 & \\
\hline PRI $\rightarrow$ ORF (total effect) & .1455 & 2.1228 & .0350 & \\
\hline PRI $\rightarrow$ ORF (direct effect) & .1038 & 1.5067 & .1335 & \\
\hline PRI $\rightarrow$ ORF (indirect effect) & .0417 & & & $(.0080 ; .1088)$ \\
\hline$R^{2}$ & \multicolumn{4}{|c|}{.1018} \\
\hline Adjusted- $R^{2}$ & \multicolumn{4}{|c|}{$.0792(\mathrm{p}<.001)$} \\
\hline \multicolumn{5}{|c|}{ Practical dimension mediated model } \\
\hline PRACTICAL $\rightarrow$ ORF & .2686 & 3.4328 & .0007 & \\
\hline PRI $\rightarrow$ PRACTICAL & .1594 & 2.6427 & .0089 & \\
\hline PRI $\rightarrow$ ORF (total effect) & .1455 & 2.1228 & .0350 & \\
\hline PRI $\rightarrow$ ORF (direct effect) & .1026 & 1.5116 & .1322 & \\
\hline PRI $\rightarrow$ ORF (indirect effect) & .0428 & & & $(.0099 ; .0881)$ \\
\hline$R^{2}$ & \multicolumn{4}{|c|}{.1172} \\
\hline Adjusted- $R^{2}$ & \multicolumn{4}{|c|}{$.0951(\mathrm{p}<.001)$} \\
\hline
\end{tabular}




\begin{tabular}{|c|c|c|c|c|}
\hline \multicolumn{5}{|c|}{ Social dimension mediated model } \\
\hline SOCIAL $\rightarrow$ ORF & .2063 & 2.5967 & .0101 & \\
\hline PRI $\rightarrow$ SOCIAL & .0987 & 1.6407 & .1024 & \\
\hline PRI $\rightarrow$ ORF (total effect) & .1455 & 2.1228 & .0350 & \\
\hline PRI $\rightarrow$ ORF (direct effect) & .1251 & 1.8395 & .0673 & \\
\hline PRI $\rightarrow$ ORF (indirect effect) & .0204 & & & $(-.0011 ; .0625)$ \\
\hline$R^{2}$ & \multicolumn{4}{|c|}{.0956} \\
\hline Adjusted- $R^{2}$ & \multicolumn{4}{|c|}{$.0729(\mathrm{p}<.01)$} \\
\hline
\end{tabular}

\subsection{Online Reseller Segments}

We replicate the three-cluster typology obtained in study 2 and each cluster exhibits similar profiles to those obtained in study 2. The examination of PRI tendencies across the three clusters is directional and reinforces the conclusion that the online aficionados cluster, is tangential to the professional reseller type identified in the literature (e.g. Chu and Liao, 2008; Chu, 2013). They are the most likely to buy a product while deliberately making the intention to resell it online in a future timeframe. In contrast to previous findings, no specific sociodemographic variable (e.g. age) characterizes any cluster. Absence of significance may owe to the smaller sample size.

\subsection{Discussion}

The results of Study 3 replicate the main effect of ORM on online resale frequency. It also replicates the piecemeal effect of each dimension of ORM on online resale frequency. Upon addition of the effect of PRI, results proved interesting. PRI were found to not directly impact ORM. The protester, generative and social factors are not significantly related to PRI, while the economic, recreational and practical dimensions are. These results are not so surprising and match previous findings in the literature. In their investigation of the PRI construct, Chu and Liao (2007, 2010) and Liao and Chu (2013) emphasized that it is the prospect of regaining the "net book value" of products (i.e. economic motive), the prediction of ease and efficiency inherent to the web (i.e. practical motive) as well as a sense of satisfaction and amusement (i.e. recreational), which made the online resale setting an especially attractive platform for reselling products intended to be resold at a future timeframe (i.e. products subject to PRI).

Our results also contribute significantly to the literature by showing that the link between PRI and online resale frequency becomes significant when ORM are taken into account. ORM are therefore useful mediators of the PRI-online resale frequency relationship.

Overall, the mere thinking of reselling a product prior to its purchase does not immediately lead consumers to engage in online resale and thus resell more frequently. But it is because consumers hold positive expectations about online resale that their PRI lead them to resell online more frequently. The positive economic, recreational and practical expected outcomes (i.e. motives), account for that relationship.

\section{General discussion and contributions of the study}

\subsection{Theoretical Contributions}

The proposed online resale measurement scale captures a variety of motives that underlie a specific form of online exchange that may apply to both the pure players (e.g. eBay), on which the whole resale is carried out online and classified ads websites (e.g. Craigslist), which require both buyers and resellers to meet. Our results enrich previous studies in several respects. First, the proposed scale offers a validated measurement tool for assessing online resellers' motivations, and classify them as sporadic experiencers, pragmatics or online aficionados resellers, across many possible combinations of products and channels. Hence, the consumer reseller category identified in previous studies (e.g. Chu and Liao, 2008; Liao and Chu, 2013), can therefore be further divided into a categorisation resembling low, medium or heavy resellers, depending on their motivational level toward online resale.

Second, by superimposing the ORM concept to the PRI construct, identified thus far, it appears that consumers may navigate across the three types of online resellers identified in previous studies - consumer, mixed role and professional resellers - (Chu and Liao, 2008; Liao and Chu, 2013). PRI determines the extent to which the professional reselling or, at least, mixed role reselling types prevails over consumer reselling. According to our results, PRI increases across the three ORM-based segments which indicate that online aficionados may in fact be more likely to engage in professional reselling who buy products mainly for resale not for self-use. The fact that sporadic experiencers show at least a moderate degree of PRI instead of none, 
weakens a monolithic categorization of online reseller, in which, for example, the consumer reseller segment is thought to resell only self-used products.

Third, the relationship between PRI and online resale behaviour is enlightened by the concept of ORM since the latter is an important mediator between the intention to resell a product and its actual resale online. While holding PRI does not directly lead to increased online resale, it is through the increase in ORM that such a relationship exists. It is actually through the envisioning of desirable economic, recreational and practical outcomes that consumers' PRI translate into heightened online resale.

Interestingly, both the economic and recreational factors were identified in offline resale literature as prompters of resale when individuals hold PRI (Sherry [1990] in flear markets; Belk et al. [1988] in swap meets). However, the practical factor was not particularly emphasized. Stone et al. (1996) underlined that practicality is salient in channels where resellers can access a large crowd of buyers such as in their study of car boot sales. Practicality in offline resale may therefore be a matter of channel type with different channels being inherently more or less practical (Gregson et al., 2007; Paden and Stell, 2005). This may explain the mitigated results found by Lemaitre and de Barnier (2015) in their exploratory study of resale motivations which was conducted regardless of channel type. They ended up by deleting a practical factor that initially emerged from their qualitative analysis.

On the Internet, there are large audiences, quasi-infinite shelf spaces, as well as sophisticated filtering capabilities (Bakos, 1997), which enhance altogether the practical aspect of online resale versus offline resale outlets. The Internet medium increased the connectivity and interactivity between buyers and resellers thus rendering the whole online resale channel more efficient and therefore more attractive for practical purposes. Such effects could not be identified in the 1970s, 1980s or early 1990s when the Internet was not yet widespread and as interactive as it has become today.

\subsection{Managerial Implications}

Most retail companies now use multichannel strategies to capitalize on both online and offline strengths (Berman and Thelen, 2004; Lapoule and Colla, 2016). They may now also wish to consider participating in the granting of 'multiple lives' to products as an additional angle to generate value. One way for doing that would be to provide an online consumer marketplace (Altimeter, 2013; Critical Vision and Crowd Companies, 2014). There is indeed nothing preventing marketing managers from listing pre-owned goods on their current retail website or perhaps separate sister site. Given ongoing consumer interest in acquiring new goods (Chu and Liao, 2007), marketing managers could institute virtual currencies in the form of vouchers for their own new products in exchange for resales, or also allow consumers to use real currency. Not only would this bolster their presence and control in an area often perceived as overwhelmingly informal, but also an online resale section adjacent to new product sections would elicit PRI, especially for high-tech and fashion goods.

Overall, consumers prefer to have easy access to all the content and functionalities they want to access to from one single location rather than from multiple ones (Lee and Cunningham, 2001). Consumers would naturally favour a Web-based structure with adjoining content sections designed to facilitate browsing (Goldenberg et al., 2012). Likewise, consumers invariably prefer to trade with well established, well known businesses (Aaker, 1992) they can trust. Combining pre-owned and new goods on a single website (e.g., Amazon) would increase consumer traffic, promote cross-selling and upselling (especially through PRIs), provide established businesses with an increased share of the growing second-hand marketplace, and foster consumer perception of durables as "liquid assets" (Chu and Liao, 2007) which are readily recoverable and upgradeable.

\subsection{Limitations and Future Research Avenues}

This study suggests several research avenues, in conjunction with recent business challenges. Firstly, this study did not examine the predictive character of the economic and practical motivations for online resale in relation to the notion of price sensitivity to products sold in conventional stores. More specifically, the Internet is a safety net in that it enables consumers to get rid easily of products and recover the purchase price of a product. This mechanism may diminish purchase resistance based on price considerations and perhaps increase impulse purchases or even compulsive buying.

Secondly, Chu and Liao (2007) identified "resale after temporary ownership" as a specific type of planned resale. It might be interesting to use ORM in conjunction with other relevant constructs such as consumer hoarding (Guillard and Pinson, 2012) or materialism (Belk, 1985), in order to identify the tipping point or the critical point at which consumers start to consider reselling the product. Since our study established a link between ORM and online frequency it may be theorized that the period of usage of the product is 
inversely proportional to the online resale motivational level, but positively proportional to hoarding or materialism scores.

\section{References}

Aaker, D.A., 1992. The value of brand equity. Journal of Business Strategy, 13(4), pp. 27-32.

Agarwal, R., and Gort., M., 1996. The evolution of markets and entry, exit and survival of firms. The Review of Economics and Statistics, 78(3), pp. 489-498.

Altimeter. 2013. A Market Definition Report: The Collaborative Economy. [online] Available at: http://fr.slideshare.net/Altimeter/the-collaborative-economy [Accessed July 2, 2015].

Anderson, J. C., and Gerbing, D. W., 1991. Predicting the performance of measure in a confirmatory factor analysis with a pretest assessment of their substantive validities. Journal of Applied Psychology, 76 (5), pp. 732-740.

Bagozzi, R.P., 1992. The self-regulation of attitudes, intentions, and behaviour. Social Psychology Quarterly 55 (2), pp. 178-204.

Bagozzi, R.P., and Warshaw, P.R., 1990. Trying to consume. Journal of Consumer Research, 17(2), pp. 127140.

Bakos, J.Y., 1997. Reducing buyer search costs: implications for electronic Marketplaces. Management Science, 43(12), pp. 1676-192.

Bandura, A., 1977. Self-efficacy: toward a unifying theory of behavioral change. Psychological Review, 84 (2), pp. 191-215.

Bandura, A., 1989. Regulation of cognitive processes through perceived self-efficacy. Developmental Psychology, 25 (5), pp. 729-735.

Barlow, A.K., Siddiqui, N.Q. and Mannion, M.. 2004. Developments in information and communication technologies for retail marketing channels. International Journal of Retail and Distribution Management, 32(3), pp. 157-163.

Belk, R. 2014. You are what you can access: Sharing and collaborative consumption online. Journal of Business Research, 67 (8), pp. 1595-1600.

Belk, R.W., 1985. Materialism: Trait aspects of living in the material world. Journal of Consumer Research, 12 (3), pp. 265-280.

Belk, R.W., Sherry, J. F. and Wallendorf, M., 1988. A naturalistic inquiry into buyer and seller behavior at a swap meet. Journal of Consumer Research, 14 (March), pp. 449-470.

Berman, B., and Thelen, S., 2004. A guide to developing and managing a well-integrated multi-channel retail strategy. International Journal of Retail and Distribution Management, 32(3), pp. 147-156.

Biswas, D., and Biswas, A., 2004. The diagnostic role of signals in the context of perceived risks in online shopping: do signals matter more on the web? Journal of Interactive Marketing, 18(3), pp. 30-45.

Bollen, K.A. 1989. Structural equations with latent variables. New-York: John Wiley and Sons.

Boyd, T.C., and McConocha, D.M., 1996. Consumer household materials and logistics management: inventory ownership cycle. Journal of Consumer Affairs, 30(1), p. 218.

Browne, M.W., and Cudeck, R., 1992. Alternative ways of assessing model fit. In Sociological Methods and Research, 21(2), edited by K. A. Bollen and S. Long, 230-258. London: Sage Publications.

Cases, A.-S. 2002. Perceived risk and risk-reduction strategies in Internet shopping. The International Review of Retail, Distribution and Consumer Research, 12 (4), pp. 375-394.

$\mathrm{Chu}, \mathrm{H}$. and Liao, S., 2007. Exploring consumer resale behavior in $\mathrm{C} 2 \mathrm{C}$ online auctions: taxonomy and influences on consumer decisions. Academy of Marketing Science Review, 11 (3), pp. 1-27.

Chu, H. and Liao, S., 2008. The Definition and Determinants of Consumer Online Resale Behavior: An Exploratory Study. International Journal of Management Perspectives, 1(1), pp. 41-48.

Chu, H. and Liao, S., 2010. Buying while expecting to sell: The economic psychology of online resale. Journal of Business Research, 63(9), pp. 1073-1078. Churchill Jr, G. A. 1979. A paradigm for developing better measures of marketing Constructs. Journal of Marketing Research, 16 (1), pp. 127-138.

D'Astous, A., Daghfous, N., Balloffet, P. and Boulaire, C., 2010. Comportement du Consommateur, 3ème édition. Québec: Chenelière Éducation.

Fornell, C., and D. F. Larcker. 1981. Evaluating Structural Equation Models with Unobservable Variables and Measurement Error. Journal of Marketing Research, 18 (1), pp. 39-50.

Gerbing, D.W. and Anderson, J.C., 1988. An updated paradigm for scale development incorporating unidimensionality and its assessment. Journal of Marketing Research, 25 (5), pp. 186-192. 
Glaser, B. and Strauss, A., 1967. The discovery grounded theory: strategies for qualitative inquiry. Chicago: Aldin.

Goldenberg, J., Oestreicher-Singer, G., and Reichman, S., 2012. The quest for content: How user-generated links can facilitate online exploration. Journal of Marketing Research, 49(4), pp. 452-468.

Gregson, N., Metcalfe, A. and Crewe, L., 2007. Moving things along: the conduits and practices of divestment in consumption. Transactions of the Institute of British Geographers, 32(2), pp. 187-200.

Guillard, V. and Pinson, C., 2012. Toward a better understanding and measurement of consumer hoarding. Recherche et Applications en Marketing (English Edition), 27(3), pp. 57-78.

Guiot, D. and Roux, D., 2010. A Second-Hand Shoppers' Motivation Scale: Antecedents, Consequences, and Implications for Retailers. Journal of Retailing, 86 (4), pp. 383-399.

Hair Jr, J.F., Black, W.C., Babin, B.J., Anderson, R.E. and Tatham, R.L., 2006. Multivariate data analysis, 6th Edition. Upper Saddle River: Prentice Hall.

Hanson, J.W., 1980. A Proposed Paradigm for Consumer Disposition Processes. Journal of Consumer Affairs 14 (Summer), pp. 49-67.

Harrell, G.D. and McConocha, D.M., 1992. Personal Factors Related to Consumer Product Disposal. Journal of Consumer Affairs, 26, pp. 397-417.

Hayes, A.F., 2013. Introduction to mediation, moderation, and conditional process analysis: A regressionbased approach. New York: Guilford Press.

Hong, W. and Thong, J.Y.L., 2013. Internet privacy concerns: An integrated conceptualization and four empirical studies. MIS Quarterly, 37 (1), pp. 275-298.

Insley, V. and Nunan, D. 2014. Gamification and the online retail experience. International Journal of Retail and Distribution Management, 42 (5), pp. 340-351.

Jacoby, J., Berning, C.K., and Dietvorst, T.F., 1977. What about disposition? The Journal of Marketing, 41 (2), pp. 22-28.

Kahneman, D., Knetsch, J.L., and Thaler, R.H., 1991. Anomalies: The endowment effect, loss aversion, and status quo bias. The Journal of Economic Perspectives, 5 (winter), pp. 193-206.

Kijiji, 2015. The Kijiji secondhand economy index: 2015 report. [online] Available at: http://secondhandeconomy.kijiji.ca/wp-content/uploads/2015/01/Kijiji-Index.pdf [Accessed June 2 2016].

Kijiji, 2016. The Kijiji secondhand economy index: 2016 report. [online] Available at: http://secondhandeconomy.kijiji.ca/wp-content/uploads/2016/02/Kijiji-Index-Report-2016.pdf [Accessed June 2 2016].

Korgaonkar, P., Petrescu, M., and Becerra, E., 2014. Shopping orientations and patronage preferences for internet auctions. International Journal of Retail and Distribution Management, 42(5), pp. 352-368.

Lapoule, P. and Colla, E., 2016. The multi-channel impact on the sales forces management. International Journal of Retail and Distribution Management, 44 (3), pp. 248-265.

Lee, M. and Cunningham, L.F., 2001. A cost/benefit approach to understanding service loyalty. Journal of Services Marketing, 15(2), pp. 113-130.

Lemaitre, N. and de Barnier, V., 2015. When consumers become merchants: Motivations, experience production and prospects. Decisions Marketing, 78, pp.1-18.

Liao, S. and Chu, H., 2013. Influence of consumer online resale awareness on purchase decisions: a mental accounting perspective. European Journal of Marketing, 47(10), pp. 1576-1597.

Liu, X., Burns, A.C., and Hou, Y., 2013. Comparing online and in-store shopping behavior towards luxury goods. International Journal of Retail and Distribution Management, 41 (11/12), pp. 885-900.

Manchanda, P., and Chu, J., 2013. An empirical study of online c2c platforms in China. Working paper, ACI Institute.

Miles, M.B., and Huberman, A.M., 1994. Qualitative data analysis: An expanded sourcebook. Thousand Oaks: Sage Publications.

Murphy, S.L., and Liao, S., 2013. Consumers as Resellers: Exploring the Entrepreneurial Mind of North American Consumers Reselling Online. International Journal of Business and Information, 8(2), pp. $183-228$

Nicholson, M., Clarke, I. and Blakemore, M., 2002. One brand, three ways to shop': situational variables and multichannel consumer behaviour. The International Review of Retail, Distribution and Consumer Research, 12 (2), pp. 131-148.

Nissanoff, D., 2006. Future Shop: How the New Auction Culture Will Revolutionize the Way We Buy, Sell, and Get the Things We Really Want. New York: The Penguin Press.

Nunnally, J.C., and Bernstein, I. H., 1994. Psychometric Theory (3rd Ed.). New York: McGraw-Hill. 
Paden, N., and Stell, R., 2005. Consumer Product Redistribution: Disposition Decisions and Channel Options. Journal of Marketing Channels, 12 (3), pp. 105-123.

Perugini, M., and Bagozzi, R.P., 2001. The role of desires and anticipated emotions in goal-directed behaviours: Broadening and deepening the theory of planned behaviour. The British Journal of Social Psychology, 40 (March), pp.79-98.

Porter, L.W., and Lawler, E.E., 1968. Managerial attitudes and performance. Thousand Oaks: University of California Press.

Prus, R., 1984. Purchasing products for resale: assessing suppliers as partners-in-trade. Symbolic Interaction, 7(2), pp. 249-278.

Rosen, K.T. and Howard, A.L., 2000. E-retail: Gold rush or fool's gold? California Management Review, 42(3), pp. $72-100$.

Shaw, D., Shiu, E., Hassan, L., Bekin, C. and Hogg, G., 2007. Intending to be ethical: An examination of consumer choice in sweatshop avoidance. In Advances in Consumer Research edited by G. Fitzsimons and V. Morwitz, pp.31-38. Duluth: Association for Consumer Research.

Sherry, J.F., 1990. A sociocultural analysis of a Midwestern American flea Market. Journal of Consumer Research, 17 (1), pp. 13-30.

Shimp, T.A. and Sharma, S., 1987. Consumer ethnocentrism: construction and validation of the CETSCALE. Journal of Marketing Research, 24 (8), pp. 280-289.

Soiffer, S.M. and Herrmann, G.M., 1987. Visions of Power: Ideology and Practise in the American Garage Sale. Sociological Review, 35 (1), pp. 48-83.

Stone, J., Horne, S. and Hibbert, S., 1996. Car boot sales: a study of shopping motives in an alternative retail format. International Journal of Retail and Distribution Management, 24 (11), pp. 4-15.

Strauss, A.L. and Corbin, J.M., 1990. Basics of qualitative research. Newbury Park: Sage.

Thaler, R., 1980. Toward a positive theory of consumer choice. Journal of Economic Behavior and Organization, 1 (1), pp. 39-60.

Top 100 Retailers, 2015. Top 100 Retailers Chart [online] Available at: https://nrf.com/2015/top100-table [Accessed May 26 2016].

Venkatesh, V., Thong, J.Y.L. and Xu, X., 2012. Consumer acceptance and use of information technology: extending the unified theory of acceptance and use of technology. MIS quarterly, 36 (1), pp. 157-178.

Vision Critical and Crowd Companies. 2014. Sharing is the new buying. Research report. Accessed July 2 2015 from http://tms.visioncritical.com/sites/default/files/pdf/sharing-new-buyingcollaborativeeconomy-report.pdf.

Vroom, V.H. 1964. Motivation and work. New York: Wiley.

Xinyan, L., Li, L. and Jingjing, W., 2010. An empirical study on the sources of C2C sellers' perceived risk and their corresponding relationship with perceived risk types. In Proceedings of the International Conference on E-Business and E-Government (ICEE), 7-9 May, Guangzhou, China.

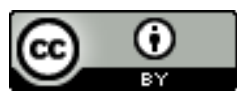

